\title{
A Passive Islanding Detection Method for Neutral point clamped Multilevel Inverter based Distributed Generation using Rate of Change of Frequency Analysis
}

\author{
Ch. Rami Reddy ${ }^{1}$ K. Harinadha Reddy ${ }^{2}$ \\ ${ }^{1}$ Department of Electrical and Electronics Engineering, K L E F, Vaddeswaram, Guntur, A.P., India. \\ ${ }^{2}$ Department of EEE, Lakki Reddy Bali Reddy College of Engineering, Mylavaram, Vijayawada, A.P., India
}

\begin{tabular}{l}
\hline Article Info \\
\hline Article history: \\
Received Jun 5, 2017 \\
Revised Dec 22, 2017 \\
Accepted Jun 11, 2018 \\
\hline
\end{tabular}

Keyword:

Boost converter Islanding detection Maximum power point tracking (MPPT)

Multilevel inverter

Neutral point clamped (NPC)

Non detection zone (NDZ)

Rate of change of frequency

Solar distributed generation

\begin{abstract}
Presently renewable energies have taken a special place in the world and most of the Distributed Generations (DGs) used in the interconnected power system are utilized, renewable energy resources. Due to the DG's advantages, including use of renewable energy such as, clean nature, does not pollute environment and having endless nature the use of these renewable resources to produce electrical energy in the world are increasing in day to day life. One problem with such Distributed generators is an unintentional islanding phenomenon. Islanding occurs when a Distributed Generation continues to energize an isolated part of a power system even after it was disconnected from the main grid, which is surrounded by unpowered lines. Since islanding can cause hazardous conditions for people and equipment which is connected to it. As per IEEE 1547 DG Interconnection standards, islanding should be quickly detected within 2 seconds, by protective relays and inverters that are part of the DG system. In this paper, a new passive method to identify islanding states has been proposed, based on the rate of change of frequency analysis (ROCOF) for a multilevel inverter based solar distributed generation systems. This method is efficient for both connecting DGs to the network with or without the Inverter. This method is more efficient than the existing methods and reducing the Non Detection Zone (NDZ), which is the disadvantage of existing passive methods and also clearly differentiating between the Islanding and Non-islanding events. The simulation results, which are carried on the MATLAB/Simulink environment shows the performance of the proposed method
\end{abstract}

Copyright $(2) 2018$ Institute of Advanced Engineering and Science. All rights reserved.

\section{Corresponding Author:}

Ch. Rami Reddy,

Department of Electrical and Electronics Engineering,

K. L. University,

Green fields, Vaddeswaram, Guntur, Andhra Pradesh, India.

Email: crreddy229@gmail.com

\section{INTRODUCTION}

Nowadays, the majority of the country's energy consumption is supplied by burning of fossil fuel resources. In this regard, they have faced with many problems, including environmental pollution and ending of fossil fuel resources. To solve this problem many countries have interest in renewable energy generation to meet their global energy consumption demand. Renewable energy, mostly includes solar energy, wind energy, energy due to the urban waste burning, biomass, streamline water flow and others. A decentralized electrical generation source connected to the distribution level of the power grid is called a Distributed Generation [1]. Major part of DGs in power systems, are from the renewable energy resources. Due to their type and nature, they can generate the energy either in the AC or DC forms. Generally, these DGs interconnect to the power grid through power switching converters [2]. Islanding occurs when a DG unit 
continues to energize certain part of the power system disconnected from the rest of the power grid. Prolonged islanding can be dangerous and even fatal to field personnel since they may not be aware that a serviced power line may still be energized by a nearby DG source, the main causes of such unintentional islanding are due to the failures detected by the grid, accidental opening of circuit breakers at the grid, intentional opening of CB for maintenance, human errors and an act of nature [3]. Standard regulations such as IEEE 1547 series and UL 1741 requires that, islanding should be detected within 2 seconds and requires the DG sources to shut down if the island load cannot be sustained and leads to variations in the voltage, frequency, current, THD, active, reactive powers outside the standards, which may hazardous to customers connected to it [4], [5]. There has been a considerable research effort to develop quick and robust islanding detection techniques, which are classified as active, passive, machine learning and remote techniques. Remote techniques such as the PLCC and SCADA require collecting information from both the utility side and DG sides to detect islanding.

PLCC monitors signals from the utility side and detect islanding when these signals are disappearing. On the other hand, SCADA detects islanding phenomenon using information from the auxiliary contacts of the circuit breakers. But these methods are costly to implement because of the need to install transceivers and other monitoring devices [6]-[8]. Active Islanding detection techniques continuously inject a form of signal into the system or change the power output reference of the DG source [9], [10]. In a gridconnected system, the grid absorbs local disturbance and no deviations are observed in the system voltage or frequency. However, in case of islanding, the disturbance can be significant, and resulting in noticeable deviation. Active detection techniques are mostly efficient, but can fail to detect islanding under certain conditions and may degrade the power quality due to the constant injection of disturbance [11]-[14].

Machine learning detection (MLD) techniques can detect islanding based on a machine learning algorithm that can be trained to detect islanding using large sets of sample data collecting islanding and non islanding events. The combination of local parameters such as voltage, frequency, power factor, THD, phase angle and others is used for training. Some popular algorithms such as Artificial Neural Networks (ANN) [15], Decision Tree Models (DT) [16], and Support Vector Machines (SVM) [17] are used to distinguish between islanding and non islanding events. In passive techniques, local parameters such as voltage, frequency, current, phase angle are monitored at the PCC level and islanding is detected if there are changes beyond a certain threshold level. Over-under voltage and over-under frequency relays (OUV/OUF) technique is a passive technique that can detect islanding when the voltage or the frequency of the system exceeds a threshold value [18]-[20]. Other popular passive techniques rely on monitoring more elaborate parameters such as rate of change of frequency, phase jump, and rate of change of reactive power [21], [22].

In this paper, a new passive method to identify islanding states has been proposed, based on the Rate of Change of Frequency analysis (ROCOF) and it also differentiates between the islanding and non islanding events. During grid connected mode, the frequency and ROCOF deviations are lesser than the threshold values, once the solar distributed generation is islanded the deviations in the frequency and ROCOF at the Point of Common Coupling (PCC) are observed at more than the threshold values and an islanding has detected. Furthermore, this technique has no NDZ limitation, and can be implemented with the existing modern DG inverters. The rest of the paper is organized as follows. System modelling is discussed in Section 2, The proposed ROCOF technique and its developments are presented in Section 3, The simulated results, and comparison with the existing methods are presented in section 4 , and conclusions are drawn in Section 5 .

\section{SYSTEM UNDER STUDY}

The test system considered as per Distribution energy sources interconnection standards, such as IEEE 1547 and UL 1741 is shown in Figure 1. When the CB is closed, the DG together with local load is connected to power network and power produced by DG is injected into the network, but when the CB is opened the DG along with the local load forms an electrical island, and the solar DG alone supplies the load demanded power and causes customer equipment to damage. In these conditions, islanding state has to be identified and power production should be disconnected within $2 \mathrm{Sec}$ after creation of the island as per interconnection standards. The simulation validation parameters are shown in Table 1. The test system shown in Figure 1 consisting of the following major parts.

\section{1. $100 \mathrm{KW}$ Solar PV panels with MPPT boost converter}

A $100 \mathrm{KW} \mathrm{PV}$ array is connected to a $120 \mathrm{KV}$ grid via a DC-DC boost converter, three phase three level Voltage Source Converter (VSC) and a step up transformer. The PV array uses 330 Sun Power modules (SPR-305E-WHT-D) in which 66 strings of 5 series connected modules are connected in parallel to produce $1 \mathrm{KW}$ power $(66 * 5 * 305.2 \mathrm{~W}=100.7 \mathrm{KW})$ with an open circuit voltage of $64.2 \mathrm{~V}$ and a short circuit current of 
$5.96 \mathrm{~A}$ at $1000 \mathrm{~W} / \mathrm{m}^{2}$ sun irradiance and $25^{\circ} \mathrm{C}$ ambient temperature. The boost converter uses Maximum Power Point Tracking technique (MPPT) to extract maximum power from the panel under irregular weather conditions, which is implemented using Incremental Conductance and Integral Regulator technique. The boost converter increases the voltage level to $500 \mathrm{~V} \mathrm{DC}$ and is given to the input of the inverter.

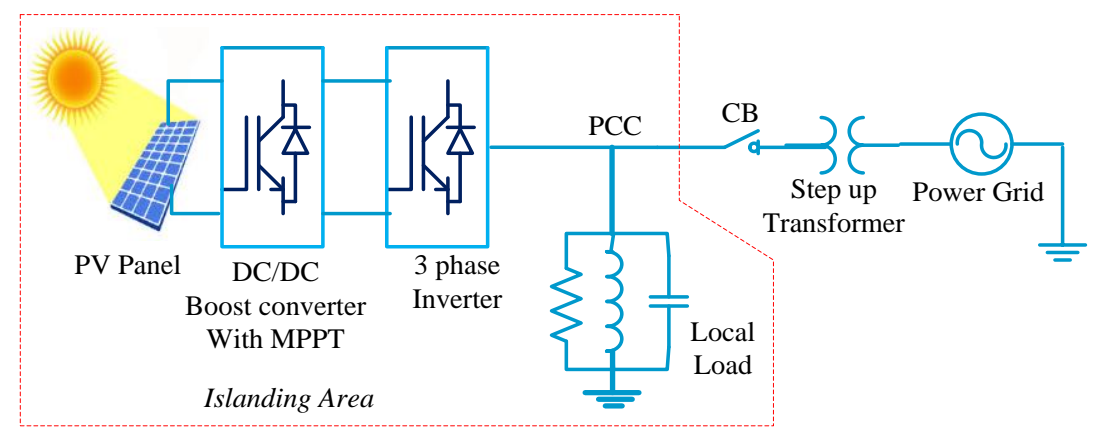

Figure 1. Block diagram of the system under study

\subsection{Three phase three level neutral point clamped multilevel inverter}

The VSC converts the $500 \mathrm{~V}$ DC link voltages to $260 \mathrm{~V}$ AC and keeps unity power factor, after which is connected to the grid via the step up transformer. Three level Neutral point clamped (NPC) inverter is shown in Figure 2, is implemented with the space vector modulation technique. On each leg, there are four active switches (Q1a, to Q4a) along with four anti parallel diodes (D1, to D4). The capacitors split the DC input on the DC side and also provide a neutral point N. When switches Q2a and Q3a are ON, the neutral point connects to the output terminal ' $\mathrm{A}$ ' through one of the clamping diodes. The voltage applied to the capacitors is E, which is V DC. In a switching state of 2, upper two switches in leg A connected and terminal voltage (VAO), then VAO become $+\mathrm{E}$, whereas ' 0 ' denotes that the lower two switches are on, then VAO becomes equal to -E. The lower switches Qa2 and Qa3 are connected to the state of 1, VAO becomes zero. Table 2 shows switching status for leg A, Leg B and leg C which have the same concept. A series RL filter is connected to the output terminals of multilevel inverter for eliminating the harmonics presented in it [21].

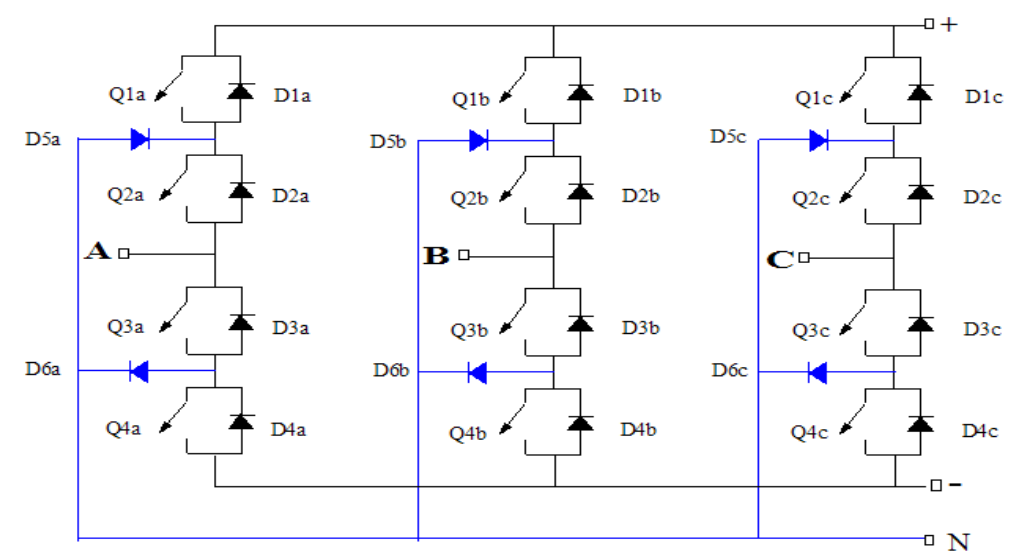

Figure 2. Three level neutral clamped multi level inverter

\subsection{Utility grid}

The power grid model shown in Figure 3 consists of a $25 \mathrm{KV}$ distribution feeder and a $120 \mathrm{KV}$ equivalent transmission system. The distribution feeder of $19 \mathrm{~km}$ is connected to two large loads $2 \mathrm{MW}, 30$ MW, along with a reactive power supply of 2 MVAR and a $120 \mathrm{KV}$ infinite bus via the substation transformer. 


\title{
3. PROPOSED INSTALNDING DETECTION ALGORITHM
}

One of the existing methods for islanding detection is based on the frequency changes at the terminals of solar DG's. The performance of the proposed algorithm is based on the measurement of frequency at PCC. The frequency measurement is done through Phase locked loop. In the cases when the grid system is lost, a change in DG's loading is happening and its instantaneous output frequency is changing called as rate of change of frequency. The Expression for the rate of change of frequency is given by [2].

$$
\frac{d f}{d t}(k)=\frac{f\left(t_{k}\right)-f\left(t_{k}-\Delta t\right)}{\Delta t}
$$

Where

$f\left(t_{k}\right)$-Measured value of frequency at the time of $\mathrm{k}^{\text {th }}$ sample i.e. $\mathrm{t}_{\mathrm{k}}$ $f\left(t_{k}-\Delta t\right)$ - Measured value of frequency, $\Delta \mathrm{t}$ before the $\mathrm{k}^{\mathrm{th}}$ sample tim e i.e. $\mathrm{t}_{\mathrm{k}}-\Delta_{\mathrm{t}}$.

Table 1. Parameters of the Test System

\begin{tabular}{lc}
\hline Name of the Parameter & Value \\
\hline Rated output of PV panels & $100 \mathrm{KW}$ \\
No of solar cells & 330 \\
Frequency & $50 \mathrm{HZ}$ \\
OC voltage of each cell & 64.2 \\
SC current of each cell & 5.96 \\
Transformer rating & $100 \mathrm{KVA}, 260 / 25 \mathrm{KV}$ \\
Utility Grid & $120 \mathrm{KV}, 2500 \mathrm{MVA}$ \\
Feeder length & $19 \mathrm{~km}$ \\
Filter Resistance & $3 \mathrm{~m} \mathrm{ohm}$ \\
Filter Inductance & $0.5 \mathrm{mH}$ \\
Shunt Capacitor & $10 \mathrm{KVAR}$ \\
\hline
\end{tabular}

Table 2. Switching states of three Phase Inverter

\begin{tabular}{|c|c|c|c|c|c|}
\hline \multirow{2}{*}{$\begin{array}{c}\text { Switching } \\
\text { state }\end{array}$} & \multicolumn{4}{|c|}{ Device switching state } & \multirow{2}{*}{$\begin{array}{c}\text { Output polel } \\
\text { Voltage } \\
\end{array}$} \\
\hline & S1 & S2 & S3 & S4 & \\
\hline 2 & on & on & off & off & $+\mathrm{E}$ \\
\hline 1 & off & on & on & off & 0 \\
\hline 0 & off & off & on & on & $-E$ \\
\hline
\end{tabular}

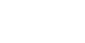

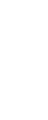


non islanding cases is presented with the results. All the simulated islanding cases were chosen to lie within the NDZ of the OUV/OUF techniques currently used for protection in modern PV inverters.

\subsection{Grid connected mode}

In grid connected mode under normal operating conditions the three level output voltage wave of the inverter, PCC voltage, current, frequency and rate of change of frequency are shown in Figure 4, Figure 5, Figure 6, and Figure 7 respectively. From Fig.6 the frequency is varied from 50.08 to 49.02 which are completely within the non detection zone. The rate of change of frequency is varying from $+5 \mathrm{~Hz} / \mathrm{Sec}$ to $-5 \mathrm{~Hz} / \mathrm{Sec}$ which is shown in Figure 7. As per islanding detection algorithm presented in this paper, the variations in frequency and rate of change of frequency are within the threshold values and the system is working in grid connected mode. If these values are more than the threshold values then an islanding state occurs.

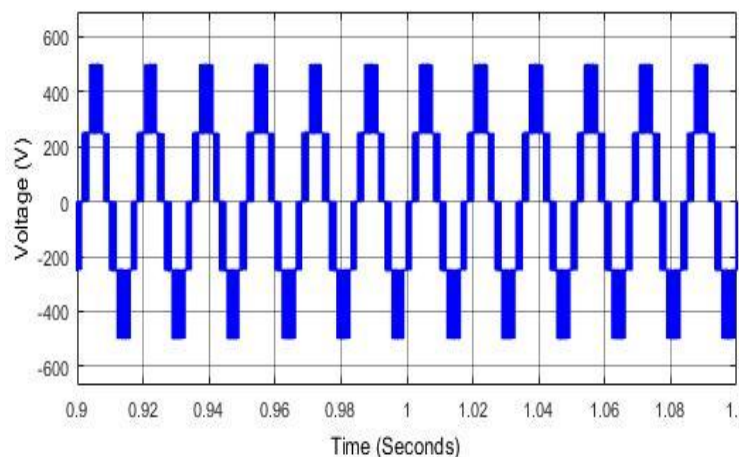

Figure 4. Simulated three level output of inverter under grid connected mode

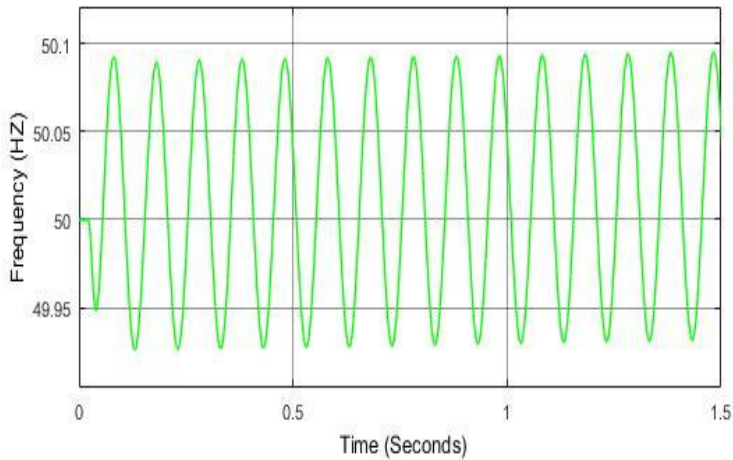

Figure 6. Simulated wave form of frequency under grid connected mode
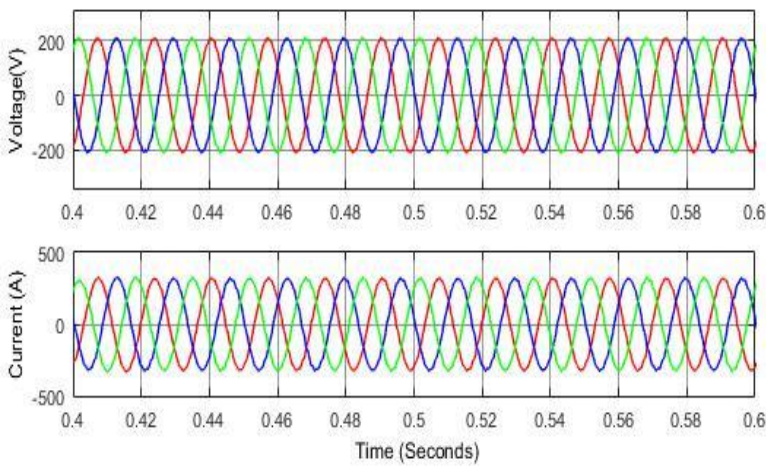

Figure 5. Simulated wave forms of Voltage and current under grid connected mode

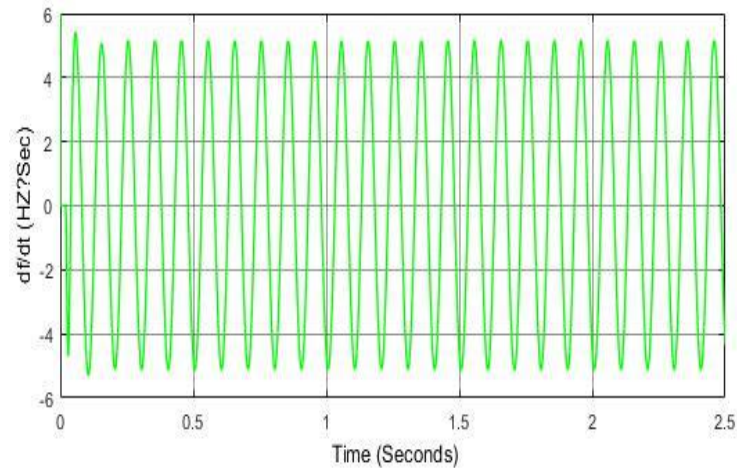

Figure 7. Simulated wave form of rate of change of frequency under grid connected mode

\subsection{Islanding mode of operation of test system}

The islanding events in this paper are simulated by considering the following cases

\subsubsection{When generation of solar DG is more than the local load}

In this test the load is considered as $10 \mathrm{KW}$, which is very less than the generation, $100 \mathrm{KW}$. At first when the $\mathrm{CB}$ is closed, the system is working in the grid connected state. At $\mathrm{t}=1 \mathrm{Sec} \mathrm{CB}$ is opened and solar photo voltaic DG together with the local load is separated and an electrical islanding condition was established as shown in Figure 1 with dotted lines. The simulation results of the three level output voltage, voltages, currents, frequency and ROCOF are shown in the Figure 8, Figure 9, Figure 10 and Figure 11 respectively. From Figure 8, when an islanding is developed at $\mathrm{t}=1 \mathrm{Sec}$, we observed the rise in voltages, which leads to the rate of rise of voltages shown in Figure 9. Due to the occurrence of islanding the currents 
at PCC are falling down after $\mathrm{t}=1 \mathrm{Sec}$. Hence, from the Figure 10 and Figure 11 the frequency and ROCOF changed, and it is observed that the ROCOF is more than the threshold value setting 10 . So islanding is detected and the proposed algorithm is working well when the load is less than the generation.

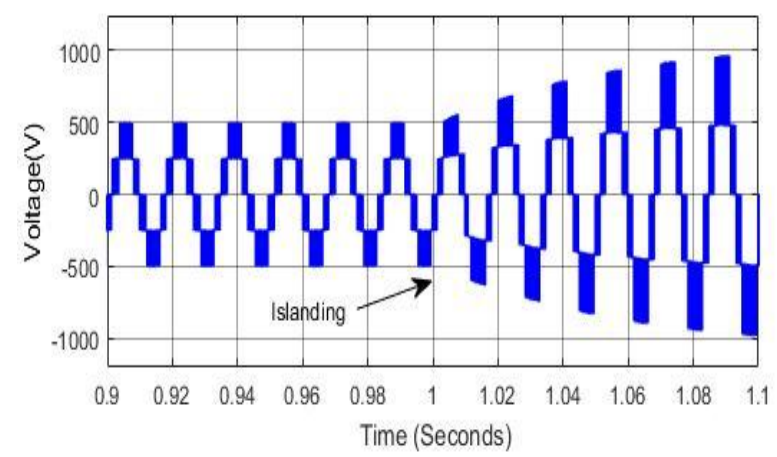

Figure 8. Simulated wave form of three level output under islanding mode when load= $10 \mathrm{KW}$
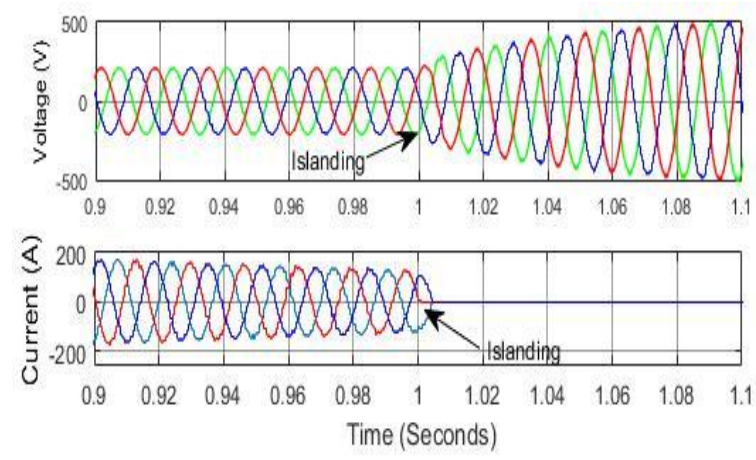

Figure 9. Simulated wave forms of voltages and currents at PCC under islanding mode when load= $10 \mathrm{KW}$

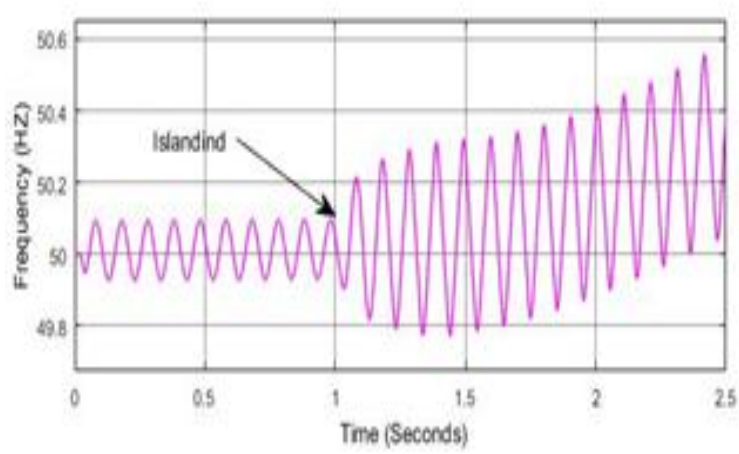

Figure 10. Simulated wave form frequency at PCC under islanding mode when load $=10 \mathrm{KW}$

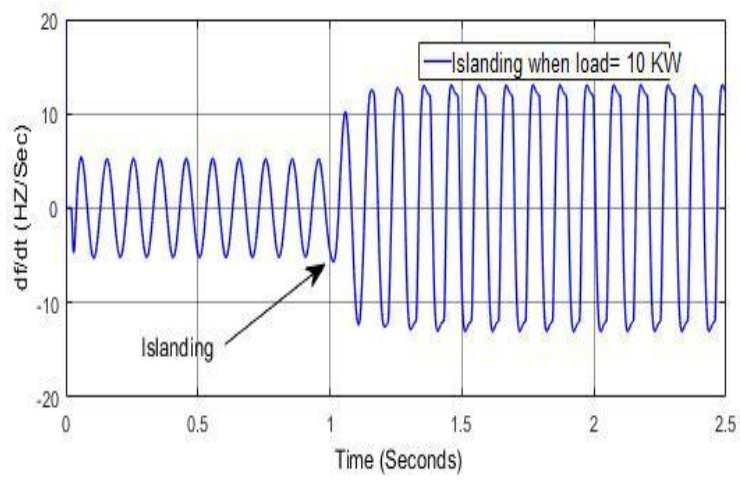

Figure 11. Simulated wave form of ROCOF at PCC under islanding mode when load $=10 \mathrm{KW}$

\subsubsection{When Generation of solar DG is equal to the local load}

In this simulation test the load is considered as $100 \mathrm{KW}$, which is equal to the generation, $100 \mathrm{KW}$. The simulated frequency and ROCOF are shown in the Figure 12 and Figure 13 respectively. From 
Figure 12, during islanding is developed at $\mathrm{t}=1 \mathrm{Sec}$, we observed the rise in frequency, which leads to the rate of rise of frequency shown in Figure 13. In this test also the ROCOF is more than the threshold value setting 10. So islanding is detected and the proposed algorithm is working well when load closely matches with the generation. The disadvantage of previous ROCOF analysis methods is, it is failing to detect islanding when load matched. Due to the use of three level inverters this difficulty is completely eliminated.

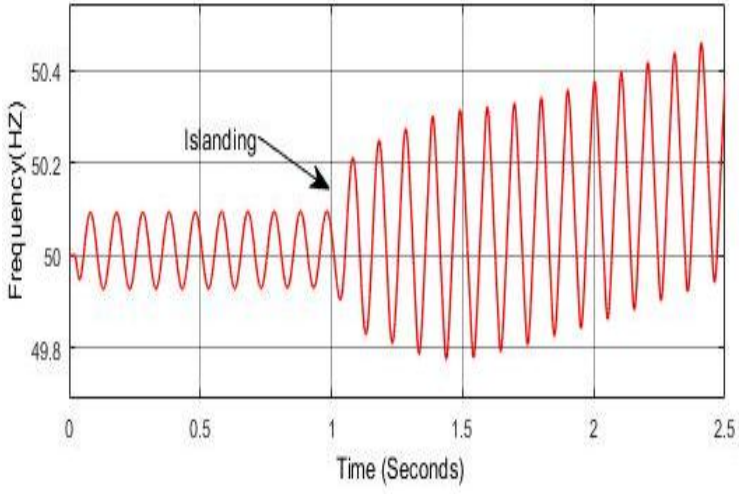

Figure 12. Simulated wave form of ROCOF at PCC under islanding mode when load $=100 \mathrm{KW}$

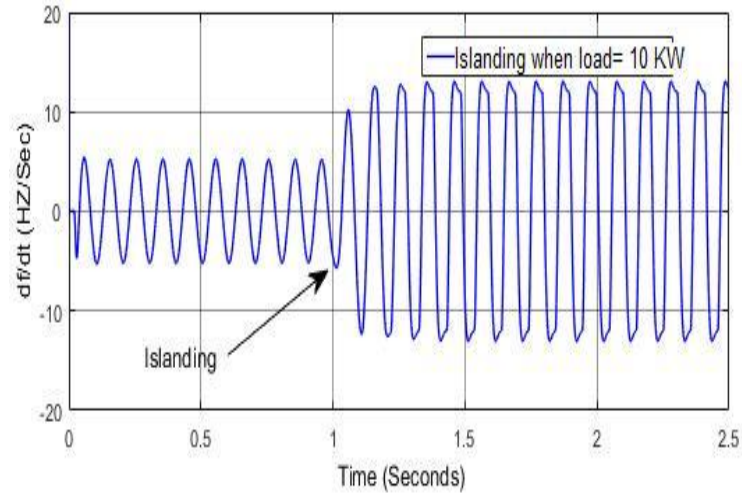

Figure 13. Simulated wave form of ROCOF at PCC under islanding mode when load $=100 \mathrm{KW}$

\subsubsection{When Generation is less than the local load}

In this simulation test the load is considered as $200 \mathrm{KW}$, which is more than the generation, 100 $\mathrm{KW}$. In this case if we failed to detect the islanding the DG cannot sustain the load and allows to flow of excessive currents which damages the DG unit. So as per IEEE 1547 standards we have to detect islanding within $2 \mathrm{Sec}$ after it was island. The simulated frequency and ROCOF are shown in the Figure 14 and Figure 15 respectively. From Figure 14, when islanding is developed at $t=1 \mathrm{Sec}$, we observed the rise in frequency, which leads to the rate of rise of frequency shown in Figure 15. In this test also the ROCOF is more than the threshold value setting 10. So islanding is detected and the proposed algorithm is working well, even when load is more than generating.

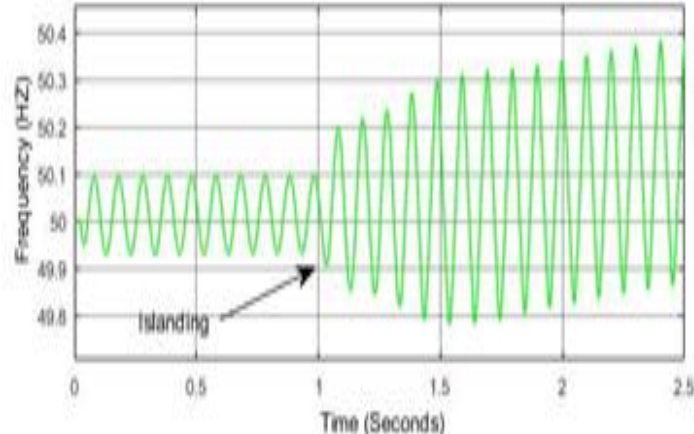

Figure 14. Simulated wave form of at PCC under islanding mode when load $=200 \mathrm{KW}$

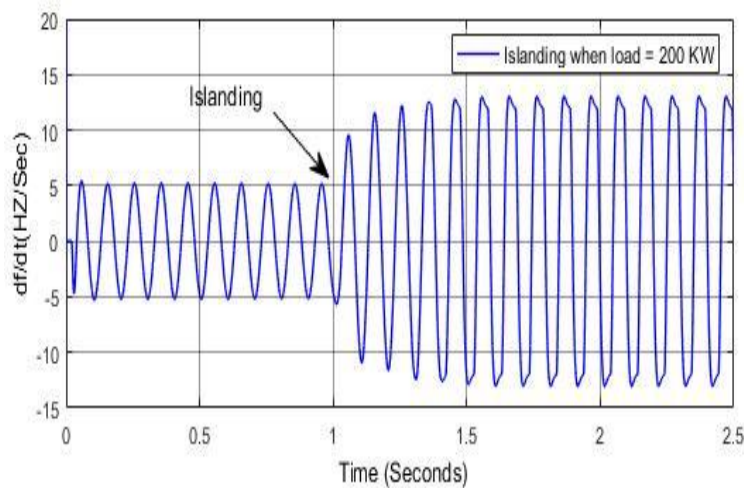

Figure 15. Simulated wave form of ROCOF at PCC under islanding mode when load $=200 \mathrm{KW}$

\subsection{Non islanding events}

In this section, the response of the proposed technique to non-islanding events are presented. The selected Non islanding events were known to cause nuisance tripping in passive detection techniques because of the high non detection zone. The major Non-islanding events in this paper are simulated by considering the following cases. 


\subsubsection{Capacitor bank switching and load switching}

In this part of the paper, to distinguish between islanding and non islanding cases and to check the performance of the proposed algorithm proposed in this paper, a non islanding case of star connected capacitor bank of $500 \mathrm{KVAR}$ and a load of $50 \mathrm{KW}$ was opened at $\mathrm{t}=1 \mathrm{Sec}$ and closed at $\mathrm{t}=2 \mathrm{Sec}$ independently. Figure 16 shows output frequency changes at PCC during switching the capacitor bank and load independently. From both the wave forms we observed that, it should not go beyond the threshold value, strictly said that it is same as grid connected mode. Hence, this state was detected properly for switching of capacitor banks and loads, so the proposed method of rate of change of frequency analysis does not act wrongly.

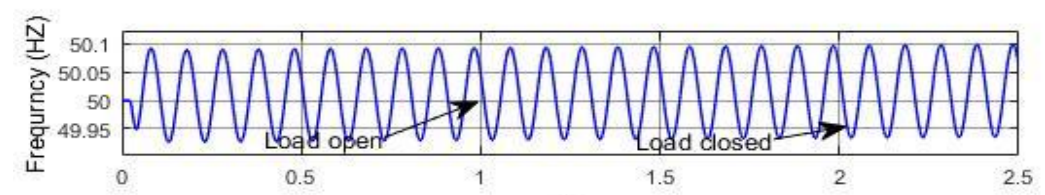

(a)

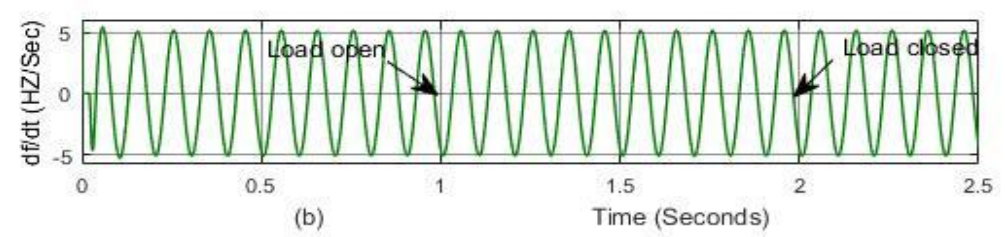

Figure 16. Simulated wave form of frequency and ROCOF at PCC during load switching

\subsubsection{Starting of induction motor}

One of the other important cases in which the proposed algorithm may wrongly detect is, starting of the Induction motor drive. In this case, an intense condition has been considered and it was shown that the algorithm in the intense modes will not mistake and could distinguish the islanding state from the other conditions. In this test, a 150 H.P induction motor is considered for the simulation. At $t=1$ Sec the motor was switched and connected to the network and is opened at $t=2$ Sec. We observed the frequency and rate of change of frequency are same as shown in Figure 16. So, this state is detected perfectly and the system will continue to work. In this test also, the proposed algorithm shows good performance as the previous non islanding cases.

\subsubsection{Switching of parallel feeders}

One of the important cases in which the proposed algorithm may wrongly detect is, switching of parallel feeders. In this case, an intense condition has been considered and it was shown that the algorithm in the intense modes will not mistake and could distinguish the islanding state from the other conditions. At $t=1$ Sec the parallel feeder was switched and connected to the network and is opened $\mathrm{at} t=2 \mathrm{Sec}$. We observed the frequency and rate of change of frequency are shown in Figure 17. Here also they are within the threshold values. So, this state is detected perfectly and the system will continue to work. In this test also, the proposed algorithm shows good performance as the previous non islanding cases.

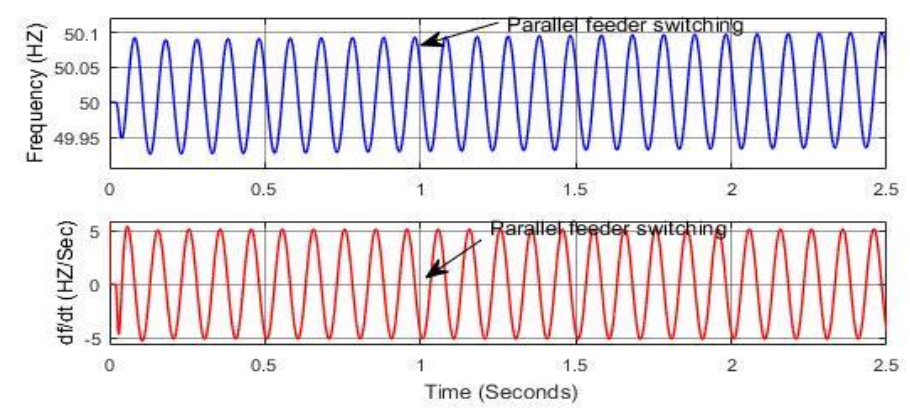

Figure 17. Simulated wave form of frequency and ROCOF at PCC during parallel feeder switching 


\subsubsection{Three phase to ground fault at PCC}

Here a three phase fault associated with the ground at the PCC is simulated. From Figure 18 it is observed that at $\mathrm{t}=1 \mathrm{Sec}$ the fault is simulated, and the changes in frequency and rate of change of frequency are observed but they do not go beyond the threshold value mentioned. So this case also detected correctly by this method. The different cases of islanding and non islanding events and with, results which are simulated in this paper are listed in Table 3.

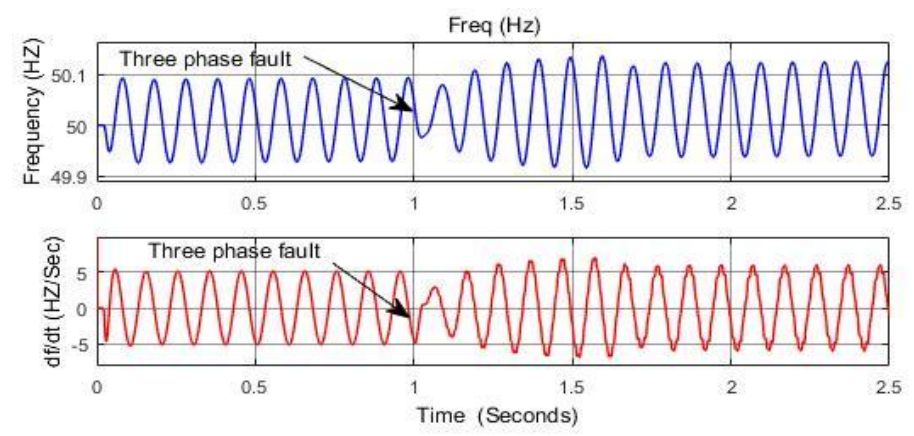

Figure 18. Simulated wave form of frequency and ROCOF at PCC during three phase fault

Table 3. Result Analysis of different Islanding and Non Islanding Events

\begin{tabular}{clc}
\hline Sl.No & Case & Result \\
\hline 1 & Load less than generation & Islanding \\
2 & Load equal to generation & Islanding \\
3 & Load more than generation & Islanding \\
4 & Switching of capacitor bank & Non Islanding \\
5 & Switching of loads & Non Islanding \\
6 & Switching of parallel feeder & Non Islanding \\
7 & Induction motor operation & Non Islanding \\
8 & LLLG fault at PCC & Non Islanding \\
\hline
\end{tabular}

\section{CONCLUSION}

In this paper a new passive method to detect islanding conditions for multilevel inverter based solar DGs was proposed. This method is essentially passive and makes decisions based on the local measurement of frequency and rate of change of frequency at PCC. This technique was modelled and implemented on a grid-connected PV system. A wide range of islanding and non islanding events such as generation matches with the load, less than the load, greater than the load, capacitor bank switching, starting of the induction motor, parallel feeder switching, three phase fault on DG terminals are tested in a realistic manner. The results show the effectiveness of the proposed method because the previous methods are wrongly worked for non islanding cases and causes nuisance tripping of inverter, but this method can easily identify and distinguish between the islanding and non islanding cases and a proper decision was sent to protect the system. The non detection zone is completely eliminated and strict islanding detection is achieved with this method.

\section{REFERENCES}

[1] Nikolaos G. Paterakis, Ozan Erdinç, Anastasios G. Bakirtzis, João P. S. Catalão, "Coordinated Operation of a Neighborhood of Smart Households Comprising Electric Vehicles, Energy Storage and Distributed Generation," IEEE Transactions on smart grid, vol. 7, no. 6, pp. 2736-2747, 2016.

[2] Farid Hashemi, Mohammad Mohammed, Amid kargirian, "Islanding detection method for microgrid based on extracted features from differential transient rate of change of frequency", IET Generation, Transmission \& Distribution, vol. 11, no. 4, pp. 891-904, March 2017.

[3] Aziah Khamis, Yan Xu , and Azah Mohamed, "Comparative Study in Determining Features Extraction for Islanding Detection using Data Mining Technique: Correlation and Coefficient Analysis”, International Journal of Electrical and Computer Engineering (IJECE), vol. 7, no. 3, pp. 1112-1124, 2017.

[4] "IEEE application guide for IEEE standards 1547(TM), "IEEE standard for inter connecting distributed resources with electric power systems," IEEE Std 1547.2-2008, pp. 1-217, April 2009. 
[5] "UL1741 standard for safety for static converters and charge controllers for use in photovoltaic power systems," Underwriters Laboratories, Jan 2001.

[6] Abbineni Sai Subhadra, P. Linga Reddy, Shailesh B. Modi, "Islanding Detection in a Distribution System with Modified DG Interface Controller," International Journal of Applied Power Engineering (IJAPE), vol. 6, no. 3, pp. 135-143, December 2017.

[7] A. Khamis "A review of islanding detection techniques for renewable distributed generation systems," Renewable and Sustainable Energy Reviews, vol. 28, no. 0, pp. 483-493, 2013.

[8] D. Velasco, C. Trujillo, G. Garcer, and E. Figueres, "Review of ant islanding techniques in distributed generators," Renewable and Sustainable Energy Reviews, vol. 14, no. 6, pp. 1608-1614, 2010.

[9] P. Gupta, R. Bhatia, and D. Jain, "Average absolute frequency deviation value based active islanding detection technique," IEEE Transactions on Smart Grid, vol. 6, no. 1, pp. 26-35, Jan 2015.

[10] Ke Jia, Hongsheng Wei, Tianshu Bi, David Thomas and Mark Sumner "An Islanding Detection Method for MultiDG Systems Based on High Frequency Impedance Estimation," IEEE Transactions on sustainable energy, vol. 8, no. 7, pp. 74-83, 2017.

[11] W. Bower and M. Ropp, "Evaluation of islanding detection methods for utility-interactive inverters in photovoltaic systems," Report SAND2002-3591, Sandia National Laboratories, 2002.

[12] Vinod John, Zhihong Ye, Amol Kolwalkar, "Investigation of Anti- Islanding Protection of Power Converter Based Distributed Generators Using Frequency Domain Analysis", IEEE Transactions on power electronics, vol. 19, no. 5, September 2004.

[13] Jou, H.-L. Chiang, W. J. and Wu, J.-C, "Virtual inductor-based islanding detection method for grid-connected power inverter of distributed power generation system," IET Renew. Power Gener, no 1, pp. 175-181, 2007.

[14] Chowdhury, S. P. Chowdhury, S. Crossley, "Islanding protection of active distribution networks with renewable distributed generators: A comprehensive survey," Electric Power Systems Research, 2009.

[15] S. Salman, D. King, and G. Weller, "Investigation into the development of a new ANN-based relay for detecting loss of mains of embedded generation," in IEEE International Conference on Developments in Power System Protection, vol. 2, pp. 579-582, April 2004.

[16] O. Faqhruldin, E. El-Saadany, and H. Zeineldin, "A universal islanding detection technique for distributed generation using pattern recognition," IEEE Transactions on Smart Grid, vol. 5, no. 4, pp. 1985-1992, July 2015.

[17] B. Matic-Cuka and M. Kezunovic, "Islanding detection for inverter based distributed generation using support vector machine method," IEEE Transactions on Smart Grid, vol. 5, no. 6, pp. 2676-2686, Nov 2014.

[18] Shashank vyas, Rajesh kumar, Rajesh kavessari "Data analytics and computational methods for anti-islanding of renewable energy based distributed generators in power grids" Renewable and Sustainable Energy Reviews, vol. 69, pp. 493-402, 2017.

[19] D. Velasco, C. Trujillo, G. Garcer, and E. Figueres, "Review of anti islanding techniques in distributed generators," Renewable and Sustainable Energy Reviews, vol. 14, no. 6, pp. 1608-1614, 2010.

[20] P.Mahat, Z. Chen, and B. Bak-Jensen, "Review of islanding detection methods for distributed generation," in Electric Utility Deregulation and Restructuring and Power Technologies (DRPT), pp. 2743-2748, April 2016.

[21] P. Satish Kumar, "FPGA Implementation of Space Vector Pulse Width Modulated Neutral Point Clamped ThreeLevel Inverter Fed Induction Motor Drive," 2015 Conference on Power, Control, Communication and Computational Technologies for Sustainable Growth (PCCCTSG), pp. 222-230, December 11-12, 2015.

[22] Keiji Wada and Hidehito Yoshida "Improvement of Power Quality for Three-Phase Grids using Single-Phase DG with Active Filter Function Units," IEEE 8th International Power Electronics and Motion Control Conference (IPEMC-ECCE Asia) ,DOI.978-1-5090-1210-7/16/\$31.00 @2016 IEEE, 2016. 